\title{
Fundamentos BÍBLICOS DE LA SEPARACIÓN DE PODERES Y FUNCIÓN CATALIZADORA DEL JUEZ*
}

\author{
Biblical Foundations for the \\ SEPARATION OF POWERS AND THE \\ Catalysing Function of Judges*
}

\author{
FundaMENTOS BÍBLICOS DA \\ SEPARAÇÃO DE PODERES E A \\ FUNÇÃO CATALISADORA DO JUIZ*
}

* Agradezco a Nicholas Aroney y a María José Viana Cleves por las valiosas ideas que aportaron a este texto, y a Sergio Severiche, quien preparó una versión casi definitiva de esta traducción al castellano del manuscrito original en inglés. / I thank Nicholas Aroney and Maria José Viana Cleves for their valuable input to this paper, and Sergio Severiche, who prepared a nearly final version of this translation into Spanish of the original English manuscript. / Agradeço a Nicholas Aroney e a María José Viana Cleves as valiosas ideias que contribuiram para este texto, e a Sergio Severiche, que preparou uma versão quase definitiva desta tradução ao espanhol do texto original em inglês.

** https://orcid.org/0000-0003-1310-8398. Magistrado, Corte Constitucional de Colombia. carloslb@corteconstitucional.gov.co

RECIBIDO: 17/O7/2019. ENVÍO A PARES: 19/07/2019 APROBADO POR PARES: 12/08/2019. ACEPTADO: 15/O8/2019

DOI: 10.5294/DIKA.2019.28.2.1 


\section{RESUMEN}

Este artículo sostiene que la Biblia fundamenta el principio de separación de poderes. En efecto, a partir de una reconstrucción conceptual de dicha noción, este trabajo defiende la tesis de que las Escrituras atribuyen a los jueces la función de incentivar a las autoridades politicas a comportarse de forma virtuosa para proteger los derechos e intereses de las personas. Las conclusiones que proporciona este artículo resultan de suma relevancia para sostener una concepción que incentive a los jueces a ejercer una función catalizadora para que las autoridades políticas efectivamente protejan los derechos e intereses de las personas mediante la creación de derecho y la formulación de políticas públicas.

\section{Palabras Clave}

División de poderes; constitucionalismo; supremacía judicial; función judicial; fundamentos cristianos de la separación de poderes. 


\section{ABSTRACT}

This article maintains that the Bible offers a sound foundation for the principle of separation of powers. From a reconstruction of the concept of 'separation of powers', this paper defends the claim that the Holy Scriptures grant judges the function of encouraging political authorities to behave virtuously in order to protect the rights and best interest of people. The conclusions of this work will be highly relevant to grasp a conception of judicial function that encourages judges to perform a catalysing role and political authorities to actually protect the rights and best interest of people by creating laws and formulating public policies.

\section{KEYWORDS}

Separation of powers; constitutionalism; judicial supremacy; judicial function; Christian foundations for the separation of powers. 


\section{RESUMO}

Este artigo argumenta que a Bíblia fundamenta o princípio de separação de poderes. A partir de uma reconstrução conceitual da noção de "separação de poderes", este trabalho defende a tese de que as Escrituras atribuem aos juizes a função de incentivar as autoridades políticas a agirem de forma virtuosa para proteger os direitos e os interesses das pessoas. As conclusões deste artigo são de suma relevância para sustentar uma concepção que incentiva os juízes a exercerem uma função catalisadora a fim de que as autoridades politicas efetivamente protejam os direitos e os interesses das pessoas mediante a criação de direito e a formulação de politicas públicas.

\section{PALAVRAS-CHAVE}

Separação de poderes.; constitucionalismo; supremacia judicial; função judicial; fundamentos cristãos da separação de poderes. 
SUMARIO: INTRODUCCIÓN. 1. LA SEPARACIÓN DE PODERES: CONCEPTO Y CONCEPCIONES. 2. LA INSTITUCIONALIZACIÓN DE UN PODER JUDICIAL INDEPENDIENTE EN LA BIBLIA. 3. LA FUNCIÓN JUDICIAL CATALIZADORA EN LA BIBLIA. 4. EL PAPEL CATALIZADOR DE LOS JUECES Y LA ADJUDICACIÓN DE LOS DERECHOS ECONÓMICOS Y SOCIALES. 5. EL PAPEL CATALIZADOR DE LOS JUECES Y LOS Límites PARA ENMENDAR LA CONSTITUCIÓN. CONCLUSIONES. BibLIOGRAFía.

\section{INTRODUCCIÓN}

Este artículo sostiene que la Biblia fundamenta el principio de separación de poderes y, en particular, una concepción de este según la cual, los jueces tienen una función catalizadora. El texto defiende la tesis de que las Escrituras atribuyen a los jueces la función de incentivar a las autoridades politicas a comportarse de forma virtuosa para proteger los derechos e intereses de las personas.

Esta tesis tiene una innegable relevancia teórica y práctica. Fija las bases de un conjunto de estrategias de diseño institucional y de prácticas de gobierno que, por una parte, se apartan de las concepciones estrictas de la separación de poderes y, por otra, incentivan a los jueces a catalizar a las autoridades políticas para proteger los derechos e intereses de las personas mediante la creación de derecho y la formulación de políticas.

Para lograr el objetivo propuesto, este artículo se estructura en cinco secciones. En la sección 1 analizaré el concepto de separación de poderes, así como algunas de sus concepciones más significativas; en particular, contrasto una concepción estricta con una concepción según la cual los jueces gozan de supremacía y desempeñan un papel catalizador. En las secciones 2 y 3 muestro cómo la Biblia fundamenta esta última concepción. En las secciones 4 y 5 destaco la relevancia teórica y práctica de esa concepción, en particular, con respecto a dos aspectos del constitucionalismo comparado contemporáneo: la aplicación judicial de los derechos fundamentales sociales y las limitaciones al ejercicio del poder para reformar la Constitución. La ilustración en esta área podría ser trasplantada, mutatis mutandi, a otros campos, tales como las limitaciones al auge de la acción del poder ejecutivo. Por último, expondré las conclusiones.

\section{LA SEPARACIÓN DE PODERES: CONCEPTO Y CONCEPCIONES}

La separación de poderes es un elemento esencial del constitucionalismo. El "constitucionalismo" es una doctrina en cuyo núcleo se encuentran dos tesis: una conceptual y una normativa. Ambas se relacionan con la idea de limitar el ejercicio del poder político por medio del derecho, con el fin de proteger los derechos individuales. La afirmación conceptual describe una forma de gobierno que se crea, estructura y limita por medio de un conjunto de normas jurídicas enmarcadas o fundamentadas en una constitución. ${ }^{1}$ Por su parte, la

1 Sobre las raíces bíblicas del constitucionalismo, véase Jonathan Burnside, "Torah and Constitutionalism" (manuscrito en poder del autor). 
tesis normativa proclama que el ejercicio del poder politico debe estar limitado por esas normas jurídicas y que las autoridades políticas deben respetar tales limitaciones. ${ }^{2}$

La separación de poderes es una estrategia necesaria para asegurar la eficacia de las limitaciones jurídicas al ejercicio del poder político, a fin de garantizar los derechos individuales. Esta necesidad es conceptual, por tanto, no puede haber constitucionalismo sin separación de poderes. Solo en virtud de la separación de poderes el legislador puede exigir responsabilidad política al Gobierno y el poder judicial puede exigir responsabilidad jurídica a las autoridades politicas, por sobrepasar los límites de sus poderes constitucionales. Por eso, según el artículo 16 de la Declaración de los Derechos del Hombre y del Ciudadano, una sociedad en la que no hay separación de poderes no tiene constitución. ${ }^{3}$ Una sociedad en la que impere el derecho y se protejan los derechos, pero que carezca de separación de poderes, tiene un orden ético, pero no un orden constitucional.

En los últimos años ha habido un debate teórico y comparativo sobre qué concepción de la separación del poder se ajusta mejor al constitucionalismo. Un elemento esencial de la separación de poderes es una triple división de competencias dentro del Estado: funcional, institucional y personal. La división funcional equivale a la individualización y distinción de las competencias para crear, ejecutar y aplicar el derecho. ${ }^{4}$ La división institucional implica facultar a tres instituciones diferentes con estas competencias: el parlamento, el Gobierno y el poder judicial. Por último, la división personal exige que diferentes funcionarios integren esas tres instituciones estatales.

Más allá de esa triple división, existen diversas concepciones de la separación de poderes. Es plausible fundamentar una clasificación con base en dos criterios: primero, qué tan rigurosa es la relación entre la división funcional e institucional; segundo, cómo las instituciones se coordinan entre sí para ejercer sus competencias. Según una concepción estricta, solo el parlamento puede crear el derecho, solo el Gobierno puede ejecutarlo y solo los jueces pueden aplicarlo. Con respecto al segundo criterio, una concepción estricta argumentaría que cada una de estas instituciones debería ejercer su poder con independencia de las demás. ${ }^{5}$

Existen concepciones menos estrictas de la separación de poderes. En un estudio reciente, por ejemplo, David Bilchitz y David Landau observan que algunas cons-

2 Wil Waluchow, "Constitutionalism”, en Edward N. Zalta (ed.), The Stanford Encyclopedia of Philosophy, 2018, en https://plato.stanford.edu/archives/spr2018/entries/constitutionalism/, fecha de consulta: 25 de enero de 2019.

3 Véase el artículo 16 de la Declaración de los Derechos del Hombre y del Ciudadano: “Una sociedad en la que la garantía de los derechos no está asegurada, ni la separación de poderes determinada, no tiene Constitución”.

4 Aristóteles, Política, Libro IV, Capítulo 14, en http://classics.mit.edu/Aristotle/politics.4.four. html, fecha de consulta: 2 de agosto de 2019.

5 Montesquieu, El Espíritu de las leyes, Libro XI, en https://oll.libertyfund.org/titles/montesquieucomplete-works-vol-1-the-spirit-of-laws, fecha de consulta: 2 de agosto de 2019. 
tituciones "tienden a [...] dar instrucciones relativamente flexibles a las instituciones políticas". ${ }^{6}$ Además, en el mundo es constatable "un auge del poder ejecutivo" y "una mengua en la legitimidad e importancia del poder legislativo". ${ }^{8}$ Asimismo, los tribunales desempeñan un "rol agresivo", 9 "al adquirir una concepción de sí mismos como una forma de control del poder ejecutivo y una opción válida para suplir los déficits democráticos". ${ }^{10}$

En la misma linea de argumentación, observaciones comparativas permiten afirmar que existe una tendencia hacia la supremacía judicial en el derecho constitucional, tanto en la teoría como en la práctica. ${ }^{11}$ En el centro del concepto de supremacía judicial se encuentra la tesis según la cual, los jueces deberían tener -y de hecho tienen-facultades constitucionales para anular las decisiones tomadas por las otras ramas del poder. ${ }^{12}$

La supremacía judicial es una concepción de la separación de poderes que ha suscitado fuertes objeciones. Por ejemplo, según Waldron, la supremacía judicial "priva a los ciudadanos comunes de sus derechos y deja de lado los preciados principios de representación e igualdad politica en la resolución final de las preguntas fundamentales relacionadas con los derechos". ${ }^{13}$ Tushnet ha argumentado que la supremacía judicial implica "una restricción sustancial al poder del pueblo para gobernarse a sí mismo". ${ }^{14}$ Esto sucede sobre todo en el ámbito de la interpretación y la aplicación de la Constitución, cuando existen varias interpretaciones razonables sobre el significado de las disposiciones constitucionales, “¿por qué la interpretación razonable de la Corte [Constitucional] debe prevalecer sobre la del legislativo (que también es razonable)?" ${ }^{15}$. Los tribunales han sido considerados como una élite injustamente empoderada y su supremacía ha sido entendida como un elemento aristocrático ajeno al sistema democrático. ${ }^{16} \mathrm{Si}$ la constitución fue hecha por el pueblo, entonces el pueblo mismo -y no los jueces- debería tener la supremacía para implementarla e interpretarla. Las interpretaciones y decisiones del pueblo y sus representantes deben ser definitivas y deben tener la capa-

6 David Bilchitz y David Landau, "Introduction: The evolution of the separation of powers in the Global South and Global North”, en David Bilchitz y David Landau (eds.), The Evolution of the Separation of Powers. Between the Global North and the Global South, Cheltenham, Elgar, 2018, p. 3

7 Ibid., p. 4

8 Idem.

9 Idem.

10 Idem

11 Nuno Garoupa, "Comparing Judicial Activism - Can we Say that the US Supreme Court is more Activist than the German Constitutional Court", Revista portuguesa de filosofia 72 (4) (2016), pp. 1089-1105; James P. Wenzel, Shaun Bowler y David J. Lanoue, "Legislating from the state bench: A comparative analysis of judicial activism”, American Politics Quarterly 25 (1997), pp. 363-379.

12 Phyllis M. Schlafty, The Supremacist: The Tyranny of Judges and Hot to Stop it. Dallas, Spence, 2004.

13 Jeremy Waldron, "The core of the case against judicial review", The Yale Law Journal 115 (2006), p. 1353.

14 Mark Tushnet, Weak Courts Strong Rights: Judicial Review and Social Welfare Rights in Comparative Constitutional Law, Princeton, Princeton University Press, 2009, pp. x-xi.

$228 \quad 15 \quad$ Id., p. 21

16 Larry Kramer, The People Themselves: Popular Constitutionalism and Judicial Review, Oxford: Oxford University Press, 2004, p. 7. 
cidad de superar, no solo las demás interpretaciones, sino incluso lo que dispone el texto constitucional.

La concepción de Locke de la separación de poderes tiene una estrecha conexión con estos argumentos. La tesis de este autor sobre la supremacía del poder legislativo tiene particular relevancia. De acuerdo con esta tesis, el legislativo debe tener la máxima autoridad sobre "cómo debe usarse la fuerza legitima en la comunidad". ${ }^{17}$ Además, Locke insistió en la supremacía del poder legislativo sobre el poder ejecutivo con el siguiente argumento: "aquel que puede dar leyes a otro, debe ser superior a él”. ${ }^{18}$ En ese ámbito Locke incluía al poder judicial dentro de su idea del poder ejecutivo, como aquel que tiene el poder de interpretar las leyes y aplicarlas a casos específicos, incluso con el uso de la fuerza. ${ }^{19}$

A pesar de la critica, varios factores han dado lugar al auge de la supremacía judicial. Entre ellos figura el hecho de que las constituciones son más amplias y detalladas, y contienen generosos y expansivos catálogos de derechos fundamentales aplicables de forma directa mediante los procedimientos abstractos y concretos de control de constitucionalidad. ${ }^{20}$ Esto ha llevado a las Cortes a aplicar los contenidos constitucionales explícitos y a determinar las disposiciones constitucionales indeterminadas.

Pese a las objeciones, connotados autores han defendido la supremacía judicial. Por ejemplo, según Schauer, una constitución es "un conjunto de reglas que imponen restricciones de segundo orden a las preferencias politicas de primer orden del pueblo, de sus representantes electos y los funcionarios ejecutivos". ${ }^{21}$ Estas restricciones de segundo orden están al servicio de los valores más profundos y perdurables del pueblo. En este marco, la supremacía judicial asegura una aplicación externa justificada de las restricciones de segundo orden; es un mecanismo para proteger a largo plazo los intereses del pueblo, de elecciones que surgen de sus propios deseos en el corto plazo. ${ }^{22}$ La interpretación judicial de estas restricciones de segundo orden debe prevalecer sobre la interpretación que el propio pueblo lleve a cabo de sus deseos a corto plazo en casos de conflicto. Como consecuencia de tener deseos a corto plazo, el pueblo se encuentra en medio de un conflicto de intereses. No tiene suficiente "separación mental" para poder analizar y decidir con justicia e imparcialidad de qué manera deben resolverse las colisiones entre los deseos a corto plazo y sus propósitos perdurables. ${ }^{23}$

17 John Locke, Two Treatises of Government, P. Laslett, ed., Cambridge, Cambridge University Press, 1988. 143.

18 Ibid., p. 150.

19 Ibid., pp. 88-89.

20 Mila Versteeg y Emily Zackin, "Constitutions unentrenched: Towards an alternative theory of constitutional design”, American Political Science Review 110 (2016), p. 657.

21 Frederick Schauer, Judicial Review and the Modest Constitution, (92) 4 CAL. L. Rev. 1045, 1046 (2004).

22 Ibid., p. 1057.

23 Idem. 


\section{LA INSTITUCIONALIZACIÓN DE UN PODER JUDICIAL INDEPENDIENTE EN LA BIBLIA}

Dentro de este marco, hay dos preguntas relevantes relacionadas con el interesante proyecto general, al que este trabajo pretende contribuir, consistente en identificar los vínculos entre el cristianismo y el constitucionalismo. Primero, si la Biblia ofrece algún fundamento para el principio de separación de poderes. Segundo, de ser así, si la Biblia proporciona las bases para una concepción de este principio, en particular, en lo concerniente a la supremacía judicial.

Con respecto a la primera pregunta, la Biblia fundamenta la institucionalización de un poder judicial independiente y describe la limitación de la autoridad política y la separación de poderes como elementos esenciales del Gobierno.

En Deuteronomio 1, Dios ordenó a Moisés que creara un poder judicial independiente, cuando el pueblo de Israel estaba a punto de tomar posesión de la tierra prometida. La creación de un poder judicial independiente fue una solución al problema práctico de resolver disputas de un ingente número de personas. ${ }^{24}$ Moisés nombró a personas "sabias y respetadas" 25 y les dio el poder de resolver las disputas de las personas y juzgarlas con imparcialidad. ${ }^{26}$ Moisés se reservó la competencia para decidir casos dificiles. ${ }^{27}$

En Éxodo 18 también se explica la creación de un poder judicial independiente para resolver el problema de administrar justicia para una cantidad considerable de personas. Jetro, el suegro de Moisés, vio que este servía como juez del pueblo "desde la mañana hasta la tarde". ${ }^{28}$ Jetro consideró que esta obra era demasiado pesada para Moisés, ${ }^{29}$ por ello, le recomendó lo siguiente:

... elige tú mismo entre el pueblo hombres capaces y temerosos de Dios, que amen la verdad y aborrezcan las ganancias mal habidas, y designalos jefes de mil, de cien, de cincuenta y de diez personas. Serán ellos los que funjan como jueces de tiempo completo, atendiendo los casos sencillos, y los casos dificiles te los traerán a ti. Eso

24 Deuteronomio 1:9-13: "En aquel tiempo les dije: 'Yo solo no puedo con todos ustedes. El Señor su Dios los ha hecho tan numerosos que hoy son ustedes tantos como las estrellas del cielo. iQue el Señor, el Dios de sus antepasados, los multiplique mil veces más, y los bendiga tal como lo prometió! ¿Cómo puedo seguir ocupándome de todos los problemas, las cargas y los pleitos de ustedes? Designen de cada una de sus tribus a hombres sabios, inteligentes y experimentados, para que sean sus jefes"”.

25 Deuteronomio 1:15.

26 Deuteronomio 1:16-17: "Atiendan todos los litigios entre sus hermanos, y juzguen con imparcialidad, tanto a los israelitas como a los extranjeros. No sean parciales en el juicio; consideren de igual manera la causa de los débiles y la de los poderosos. No se dejen intimidar por nadie, porque el juicio es de Dios. Los casos que no sean capaces de resolver, tráiganmelos, que yo los atenderé”.

27 Idem

28 Éxodo 18:13: "Al día siguiente, Moisés ocupó su lugar como juez del pueblo, y los israelitas estuvieron de pie ante Moisés desde la mañana hasta la noche”.

23029 Éxodo 18:17-18: "El suegro de Moises respondió 'No está bien lo que estás haciendo, pues te cansas tú y se cansa la gente que te acompaña. La tarea es demasiado pesada para ti; no la puedes desempeñar tú solo”." 
te aligerará la carga, porque te ayudarán a llevarla. Si pones esto en práctica y Dios así te lo ordena, podrás aguantar; el pueblo, por su parte, se irá a casa satisfecho. ${ }^{30}$

Según las Escrituras, Moisés escuchó a su suegro e hizo todo lo que dijo:

... Moisés atendió a la voz de su suegro y siguió sus sugerencias. Escogió entre todos los israelitas hombres capaces, y los puso al frente de los israelitas como jefes de mil, cien, cincuenta y diez personas. Estos jefes fungian como jueces de tiempo completo, atendiendo los casos sencillos. A Moisés remitían los casos difíciles. ${ }^{31}$

La creación de un poder judicial independiente tuvo lugar mucho antes de la institucionalización del reino y de la figura del rey. Esto podría interpretarse como una señal de preeminencia del primero sobre el segundo. ${ }^{32}$

Asimismo, el Antiguo Testamento destaca la limitación de la autoridad política y la separación de poderes como elementos esenciales del Gobierno. En Deuteronomio 17 se describe una separación entre Dios, que es el dador de la ley, ${ }^{33}$ los tribunales, que fueron facultados con la función de juzgar y decidir las disputas, ${ }^{34}$ y el rey, elegido de acuerdo con los criterios fijados por Dios, ${ }^{35}$ y cuyas decisiones están limitadas por la ley. ${ }^{36}$

Otros apartes de las Escrituras reiteran y realzan el principio según el cual el poder del rey está limitado de manera normativa y empírica. Por un lado, el salmo 72 prescribe que el rey debe ejercer su poder para alcanzar la justicia. ${ }^{37}$ Además, en 1Crónicas 28:8, David le pide a su sucesor, Salomón, que "tenga cuidado de seguir todos los mandamientos del Señor su Dios". ${ }^{38}$ De la misma manera, según Deuteronomio, el rey no debe adquirir "muchos caballos para sí mismo". Esto habla de un poder limitado en el uso de la fuerza. El nuevo testamento reitera el

30 Éxodo 22-23.

31 Éxodo 18:25-26.

32 Jonathan Burnside, "Torah and Constitutionalism", cit.

33 Deuteronomio 17:3: Dios habla sobre "mi mandamiento". Deuteronomio 17:2-4: "Puede ser que a algún hombre o mujer entre los tuyos, habitante de una de las ciudades que el Señor tu Dios te dará, se le sorprenda haciendo lo que ofende a Dios. Tal persona habrá violado el pactoy desobedecido mi orden, al adorar a otros dioses e inclinarse ante ellos o ante el sol, la luna o las estrellas del cielo. Tan pronto como lo sepas, deberás hacer una investigación minuciosa”.

34 Deuteronomio 17:8: "Si te enfrentas a casos demasiado difíciles de juzgar, tales como homicidios, pleitos, violencia y otros litigios que surjan en las ciudades, irás al lugar que el Señor tu Dios elija”.

35 Deuteronomio, 17:15: “...asegúrate de nombrar como Rey a uno de tu mismo pueblo, uno que el Señor tu Dios elija".

36 Deuteronomio, 17:18-20: "Cuando el rey tome posesión de su reino, ordenará que le hagan una copia del libro de la ley, que está al cuidado de los sacerdotes levitas. Esta copia la tendrá siempre a su alcance y la leerá todos los días de su vida. Así aprenderá a temer al Señor su Dios, cumplirá fielmente todas las palabras de esta ley y sus preceptos, no se creerá superior a sus hermanos ni se apartará de la ley en el más mínimo detalle, y junto con su descendencia reinará por mucho tiempo sobre Israel".

37 Salmos 72:1-2: "Oh Dios, otorga tu justicia al rey, tu rectitud al príncipe heredero. Así juzgará con rectitud a tu pueblo y hará justicia a tus pobres”.

38 1Crónicas 28:8: "En presencia de Dios que nos escucha, y de todo Israel, que es la congregación del Señor, hoy les encarezco que obedezcan cumplidamente todos los mandamientos del Señor su Dios. Así poseerán esta hermosa tierra y se la dejarán en herencia perpetua a sus hijos". 
carácter limitado del Gobierno, en particular, al describir a las autoridades como servidoras de la comunidad y del bien común, ${ }^{39}$ que han sido designadas por Dios para cumplir sus cometidos. ${ }^{40}$

En cuanto a la separación de poderes, Burnside argumenta que en diversos pasajes de Deuteronomio 16, 17 y 18 se instituye un sistema de separación de poderes, y de controles y equilibrio entre cuatro tipos de autoridades: "los jueces (16:18-17:13); el rey (17:14-20); los sacerdotes (18:1-13) y los profetas (18:14-22)". ${ }^{41}$ Burnside destaca que esta era una manera en que el pueblo de Israel podía distanciarse del sistema de Gobierno que soportaban en Egipto. En contraste con el faraón autoritario, los israelitas establecieron un sistema en el que una sola autoridad humana nunca podría concentrar todo el poder político. ${ }^{42}$ Además, como señala Ekins, la limitación del poder del rey está alineada con la advertencia de Dios sobre el riesgo de que el gobierno de un rey conduzca al abuso. ${ }^{43}$

\section{LA FUNCIÓN JUDICIAL CATALIZADORA EN LA BIBLIA}

Con respecto a la segunda pregunta, el Antiguo Testamento también describe cómo los profetas hacían responsable al rey, en cuanto al respeto de los límites que las leyes de Dios fijaban al poder del Gobierno. Aquí quisiera defender la tesis de que, según la Biblia, los profetas constituian una rama independiente del poder político, encargada de ejercer una función catalizadora. Con ayuda de algunos ejemplos ilustraré el significado y el alcance de esa función. También fundamentaré la idea de que el poder judicial debe cumplir esta función en la actualidad.

De acuerdo con el Antiguo Testamento, los profetas eran personas virtuosas, que desempeñaban una función catalizadora: incentivar al rey para que respetara los mandamientos de Dios y gobernara con justicia. La Biblia contiene ejemplos interesantes de cómo los profetas desempeñaron esta función catalizadora. Entre ellos cuentan los episodios en que Samuel ${ }^{44}$ y Natán ${ }^{45}$ responsabilizaron, de forma

39 Richard Ekins, "Self-Government and the Kingdom of Heaven" (manuscrito en poder del autor).

40 Romanos 13:1: "Todos deben someterse a las autoridades públicas, pues no hay autoridad que Dios no haya dispuesto, así que las que existen fueron establecidas por él". Véase también Romanos 13:4: "Aquel que tiene autoridad está al servicio de Dios para tu bien. Pero, si haces lo malo, entonces debes tener miedo. No en vano lleva la espada, pues está al servicio de Dios para impartir justicia y castigar al malhechor".

41 Jonathan Burnside, "Torah and Constitutionalism", cit.

42 Idem.

43 Richard Ekins, "Self-Government and the Kingdom of Heaven", cit.

44 1Samuel 15:22-23: “¿Qué le agrada más al Señor: que se le ofrezcan holocaustos y sacrificios o que se obedezca lo que Él dice? El obedecer vale más que el sacrificio y el prestar atención vale más que la grasa de los carneros. La rebeldía es tan grave como la adivinación y la arrogancia, como el pecado de la idolatría. Y, como tú has rechazado la palabra del Señor, Él te ha rechazado como rey".

45 2Samuel 12:7-10: "Entonces Natán le dijo a David: ‘Tú eres ese hombre! Así dice el Señor, Dios de Israel: Yo te ungi como rey sobre Israel, y te libré del poder de Saúl. Te di el palacio de tu amo, y puse sus mujeres en tus brazos. También te permití gobernar a Israel y a Judá. Y por si esto hubiera sido poco, te habría dado mucho más. ¿Por qué, entonces, despreciaste la palabra del Señor haciendo lo que le desagrada? ¡Asesinaste a Urías el hitita para apoderarte de su esposa! ¡Lo mataste con la espada de los amonitas! Por eso la espada jamás se apartará de tu familia, pues me despreciaste al tomar la esposa de Urías el hitita para hacerla tu mujer”. 
respectiva, a Saúl y a David por violar los mandamientos de Dios. En el segundo episodio Natán catalizó el arrepentimiento de David y el perdón de Dios. ${ }^{46}$

Estos ejemplos también muestran cómo la Biblia fundamenta una supremacía de los profetas sobre el rey. Los profetas tenían la función de interpretar las leyes de Dios; para ello, intentaban desentrañar cuál era su voluntad. ${ }^{47} \mathrm{El}$ diálogo entre Samuel y Saúl revela que, ante la incompatibilidad entre la interpretación de la voluntad de Dios que hiciera el rey y la de un profeta, prevalecía la última. Dios ordenó a Saúl que "atacara a los Amalecitas y destruyera totalmente todo lo que les pertenecía”. Añadió: "no les tengas compasión. Mátalos a todos, hombres y mujeres, niños y recién nacidos, toros y ovejas, camellos y asnos". ${ }^{48}$ Sin embargo, Saúl y el ejército "le perdonaron la vida al rey Agag y preservaron las mejores ovejas y vacas, los terneros más gordos y, en fin, todo lo que era de valor". ${ }^{49}$ Cuando Samuel inquirió a Saúl, el rey interpretó sus acciones como si estas fueran idóneas para cumplir el mandato de Dios. Adujo lo siguiente: "[las ovejas que escuchas] son las que nuestras tropas trajeron del país de Amalec. Dejaron con vida a las mejores ovejas y vacas para ofrecerlas al Señor tu Dios, pero todo lo demás lo destruimos". ${ }^{50}$ A pesar de eso, Samuel responsabilizó a Saúl de desobedecer el mandato de Dios. ${ }^{51}$ Saúl respondió de la siguiente manera: "Pero yo obedecí al Señor", dijo Saúl: "He cumplido la misión que él me encomendó. Traje prisionero a Agag, rey de Amalec, pero destruí a los amalecitas. Y del botín, los soldados tomaron ovejas y vacas con el propósito de ofrecerlas en Guilgal al Señor tu Dios”. ${ }^{52}$ La interpretación de Samuel prevaleció sobre la de Saúl. Samuel respondió a Saúl:

¿Qué le agrada más al Señor: que se le ofrezcan holocaustos y sacrificios o que se obedezca lo que Él dice? El obedecer vale más que el sacrificio y el prestar atención vale más que la grasa de los carneros. La rebeldía es tan grave como la adivinación y la arrogancia, como el pecado de la idolatría. Y, como tú has rechazado la palabra del Señor, Él te ha rechazado como rey. ${ }^{53}$

46 2Samuel 12:13: “Después David reconoció ante Natán, 'He pecado contra el Señor”.

47 Éxodo 18:15: "Moisés le respondió a él [Jetro], "Es que el pueblo viene a ver para consultar la voluntad de Dios. Cuando tienen algún problema, me lo traen a mí para que yo dicte sentencia entre las dos partes. Además, les doy a conocer las leyes y las enseñanzas de Dios”.

481 Samuel 15:1-3. "Samuel le dijo a Saúl: 'El Señor me envió a ungirte como rey sobre su pueblo Israel. Así que pon atención al mensaje del Señor. Así dice el Señor Todopoderoso: He decidido castigar a los amalecitas por lo que le hicieron a Israel, pues no dejaron pasar al pueblo cuando salía de Egipto. Así que ve y ataca a los amalecitas ahora mismo. Destruye por completo todo lo que les pertenezca; no les tengas compasión. Mátalos a todos, hombres y mujeres, niños y recién nacidos, toros y ovejas, camellos y asnos"”.

49 1Samuel 15:9.

50 1Samuel 15:15.

51 1Samuel 15:19. Samuel le dijo a Saúl: "Por qué, entonces, no obedeces al Señor?" 
Saúl, entonces, aceptó la interpretación de Samuel. ${ }^{54}$ Dios también dio la razón a Samuel: destronó a Saúl y entronizó a David. ${ }^{55}$

Otros ejemplos también ilustran la relación entre la función catalizadora de los profetas y su supremacía sobre el rey. En 1Reyes 13 un profeta amonestó a Jeroboán después de que el rey había inducido a la gente a adorar becerros de oro en el altar de Betel. El profeta gritó que el altar se rompería. Entonces, el rey ordenó capturar al profeta estirando su mano. Sin embargo, en ese momento la mano del rey se secó, de modo que no pudo retraerla. Por esta razón, los reyes pidieron al profeta que orara por la restauración de la mano. Después de la oración Dios respaldó al profeta y restauró la mano del rey.

Asimismo, en 1Reyes 21, tentado por Jezabel, Acab indujo a la gente a apedrear a Nabot e ilegítimamente se apoderó su viña. Entonces, Elías amonestó a Acab y le advirtió sobre el castigo de Dios. Esta amonestación catalizó el arrepentimiento de Acab y la misericordia de Dios. ${ }^{56}$ Además, en 1Reyes 18:41-46, Elias reconvino a Acab antes del final de la sequía. Dios avaló a Elías enviando fuertes lluvias. Por último, en 1Reyes 20, después de que Ben Adad, rey de Aram, atacó a Samaria y amenazó a Israel, un profeta incentivó a Acab para comenzar la batalla contra Ben Adad y, a pesar del poder del ejército de Aram, Acab obedeció y se irguió victorioso.

Mutatis mutandi, en el marco del constitucionalismo, los jueces deben desempeñar esta función catalizadora. La estructura de la representación democrática, basada en elecciones libres llevadas a cabo al culmen de costosas campañas, financiadas por todo tipo de fuentes, podría llevar a las autoridades políticas a actuar para proteger intereses distintos a los correspondientes al bien común y la satisfacción de los derechos de los individuos. También puede haber puntos ciegos y obstáculos burocráticos que creen dificultades para lograr esos objetivos. En ese tipo de escenarios, los jueces deberian alentar a las autoridades politicas para buscar el bien común y proteger los derechos individuales. Los jueces también deben dar visibilidad jurídica y politica a problemas sociales ocultos y crear incentivos para la eliminación de los obstáculos burocráticos para solucionarlos.

Por tanto, en contra de una concepción estricta de la separación de poderes según la cual, el papel de los jueces es "invisible" ${ }^{57}$ y secundario, la Biblia podría fundamentar una concepción de un poder judicial supremo, provisto de la com-

54 1Samuel 15:24: "Después Saúl le dijo a Samuel: "He quebrantado el mandato del Señor y tus instrucciones".

55 1Samuel 16:1: "El Señor le dijo a Samuel, ¿¿Cuánto tiempo vas a quedarte llorando por Saúl, si ya lo he rechazado como rey de Israel? Mejor llena de aceite tu cuerno, y ponte en camino. Voy a enviarte a Belén, a la casa de Isaí, pues he escogido como rey a uno de sus hijos”. David fue el elegido.

56 1Reyes 21:29: “¿Has notado cómo Acab se ha humillado ante mí? Por cuanto se ha humillado, no enviaré esta desgracia mientras él viva, sino que la enviaré a su familia durante el reinado de su hijo".

$234 \quad 57 \quad$ En El espíritu de las leyes, Montesquieu describe el papel de los jueces de la siguiente manera: "Los jueces deben ser 'no más que la boca que pronuncia las palabras de la ley, simples seres pasivos, incapaces de moderar su fuerza o rigor", en https://oll.libertyfund.org/titles/montesquieucomplete-works-vol-1-the-spirit-of-laws, fecha de consulta: 21 de febrero de 2019. 
petencia para desempeñar una función catalizadora. Es posible caracterizar la función catalizadora con tres propiedades esenciales que, por ejemplo, se encuentran en el diálogo entre Natán y David. Primero, existe diálogo y cooperación entre el juez y la autoridad política. Segundo, este diálogo genera un direccionamiento virtuoso de la autoridad política. Y tercero, el diálogo implica que la intervención del juez en el poder de la autoridad política sea débil. Sin embargo, el juez conserva su supremacía.

Quisiera argumentar que el ejercicio de esta función catalizadora es crucial en relación con algunos problemas contemporáneos del derecho constitucional. Algunos ejemplos son: limitar el auge del poder ejecutivo, limitar el poder de las autoridades políticas para reformar la constitución y orientar la aplicación judicial de los derechos fundamentales sociales. En estas tres áreas, los jueces deben cooperar e incentivar a las autoridades políticas para que actúen de forma virtuosa en el diseño e implementación de políticas que conduzcan, respectivamente, al logro del bien común y el respeto de las libertades, la preservación del constitucionalismo democrático en los cambios constitucionales, y la reducción de la desigualdad y la pobreza mediante la protección de los derechos fundamentales sociales. A continuación, abordaré los dos últimos asuntos.

\section{EL PAPEL CATALIZADOR DE LOS JUECES Y LA ADJUDICACIÓN DE LOS DERECHOS ECONÓMICOS Y SOCIALES}

Los jueces deben promover la actividad de las autoridades politicas en el diseño e implementación de estrategias que permitan satisfacer las necesidades básicas de todos los ciudadanos y reducir la desigualdad. El afianzamiento constitucional de los derechos fundamentales sociales es un mecanismo, adoptado en todo el mundo, y en particular, en el llamado "Sur Global", para lograr esos objetivos. Las constituciones protegen los derechos fundamentales sociales de varias formas. Aquellas que pertenecen al primer constitucionalismo liberal incluían disposiciones que institucionalizaban lo que Mark Tushnet llamaba derechos "no justiciables" o "derechos meramente declarativos", es decir, derechos que los tribunales no podian aplicar. ${ }^{58}$ Varias constituciones actuales aún instituyen los derechos fundamentales sociales de esa manera. ${ }^{59}$ Sin embargo, la mayoria de las constituciones reales institucionalizan derechos fundamentales sociales justiciables. ${ }^{60}$

58 Tushnet, Weak Courts, Strong Rights, op. cit., p. 238.

59 Por ejemplo, según el artículo 53.3 de la Constitución Española de 1978, las disposiciones constitucionales de los derechos económicos y sociales "deben guiar la legislación, la práctica judicial y las acciones de las autoridades públicas”. Estas disposiciones corresponden al Capítulo 3 de la Parte I de la Constitución Española, titulada: "Principios que rigen la Política Económica y Social". Las disposiciones de este capítulo garantizan los derechos económicos y sociales de la familia, los niños y las madres (art. 39), los trabajadores (arts. 40, 41 y 42), las personas con discapacidad (artículo 49) y los ancianos (art. 50), así como los derechos a la salud (art. 43) y la vivienda (art. 47).

60 Courtney Jung, Ran Hirschl y Evan Rosevear, "Economic and social rights in national constitutions", American Journal of Comparative Law 62 (4) (2014). 
El debate central sobre la aplicación judicial de los derechos fundamentales sociales gira en torno al papel de los jueces. Los tribunales de última instancia en todo el mundo han concebido su papel de diferentes maneras. Por ejemplo, la primera jurisprudencia desarrollada por el Tribunal Constitucional de Sudáfrica en la solución de casos de derechos sociales, bajo la óptica de los artículos 26.2 y 27.2 de la Constitución sudafricana de 1996, refleja una concepción en la que los jueces llevan a cabo un control judicial débil, acerca de la razonabilidad de las medidas adoptadas por las autoridades politicas para aplicar los mencionados derechos. Una concepción estricta del principio de separación de poderes fundamenta este tipo de control judicial, altamente respetuoso de las competencias de las autoridades políticas. ${ }^{61}$ Con todo, algunos críticos han apuntado que esta concepción de la función judicial es incapaz de ofrecer una protección adecuada de los derechos sociales. ${ }^{62}$

En contraste, los tribunales latinoamericanos se conciben, a sí mismos, como instituciones capitales para la satisfacción de los derechos fundamentales sociales. Dichas cortes aducen que, debido a la incapacidad o falta de interés de las autoridades políticas, estos derechos no se han implementado mediante políticas públicas. Por ello, se consideran legitimadas para sobrepasar los limites de la separación de poderes e impartir órdenes fuertes, que incluyen a veces la implementación de políticas y programas diseñadas por los propios jueces. Algunas de esas medidas buscan proteger el núcleo minimo de los derechos fundamentales sociales, núcleo que consiste en un conjunto de beneficios específicos que deben satisfacerse bajo cualquier circunstancia. Asimismo, en particular en los llamados casos estructurales, algunas otras medidas equivalen a órdenes dirigidas a las autoridades politicas para que implementen medidas jurídicas, financieras y administrativas apropiadas para garantizar que el Estado cumpla con las obligaciones que tales derechos entrañan.

La jurisprudencia de la Corte Constitucional de Colombia ofrece una variedad de ejemplos en que los jueces han impartido fuertes medidas dirigidas a la protección del núcleo mínimo de los derechos fundamentales sociales. Por ejemplo, la Corte adoptó la doctrina del mínimo vital, según la cual, cada ciudadano tiene el derecho fundamental a disfrutar de los medios necesarios para llevar una subsistencia digna. ${ }^{63}$ En este sentido, el estándar del núcleo mínimo es diferente al de la razonabilidad. Mientras aquel justifica que los tribunales determinen la cantidad

61 Véase, por ejemplo, Minister of Health v Treatment Action Campaign (No. 2) 20025 SA 721 (CC), paras. 30-39. Véase también, Sandra Liebenberg, Socio-Economic Rights: Adjudication under a Transformative Constitution, Cape Town, Juta, 2010, p. 132.

62 Véase, entre otros, David Bilchitz, Poverty and Fundamental Rights: The Justification and Enforcement of Socio-Economic Rights, Oxford, Oxford University Press, 2007, p. 187; Anashri Pillay, "Economic and social rights adjudication: Developing principles of judicial restraint in South African and the United Kingdom", Public Law 3, 2013; y Carol Steinberg, "Can reasonableness protect the poor? A review of South Africa's socio-economic rights jurisprudence”, South African Law Journal 123 (2006).

63 Véase, entre otros, las siguientes sentencias de la Corte Constitucional colombiana: SU-559/1997, T-068 y T-153/1998, T-025/2004, T-760/2008, SU-090 у T-068/2010. 
y la calidad mínima de los bienes y servicios que las autoridades politicas deben entregar a los individuos, este reconoce que solo el Legislativo y el Ejecutivo están facultados para determinar cuál debe ser el monto minimo. Los jueces deben ser respetuosos de esta fijación política, a menos que sea irrazonable. La jurisprudencia de la Corte colombiana también proporciona ejemplos de diseño judicial de políticas sociales para solucionar problemas estructurales. Los tres casos más importantes se refieren a políticas relacionadas con los derechos de los reclusos, ${ }^{64}$ los desplazados, ${ }^{65} \mathrm{y}$ el derecho a la salud. ${ }^{66}$

Esta práctica judicial ha suscitado fuertes objeciones. Las criticas comprenden las preocupaciones institucionales relacionadas con la falta de capacidad de los tribunales para evaluar demandas de beneficios fundadas en los derechos fundamentales sociales. ${ }^{67}$ También expresan reservas acerca de la compatibilidad entre esta práctica judicial, por una parte, y los principios del Estado de derecho, la separación de poderes y los fundamentos de la democracia representativa, por otra. ${ }^{68}$ Asimismo, se ha discutido la efectividad de esta práctica judicial activista para alcanzar los objetivos mencionados, relacionados con la satisfacción de las necesidades básicas y la eliminación de la desigualdad. Existe evidencia de que, al menos en algunos países latinoamericanos, la aplicación constitucional de los derechos fundamentales sociales no ha beneficiado a los más pobres. Más bien, ha mejorado las circunstancias económicas de ciudadanos de clase media que, de alguna manera, son capaces de satisfacer sus necesidades básicas mediante métodos ordinarios de mercado. ${ }^{69}$

Una estrategia fructífera, diseñada sobre la base de la función catalizadora de los jueces, podría llevar a los tribunales constitucionales a ofrecer una protección más efectiva de los derechos fundamentales sociales. Esta estrategia también podría ser menos invasiva para la separación de poderes. Tal como Natán se acercó a David y catalizó una reacción que lo llevó a arrepentirse, los tribunales deben dialogar y cooperar con otras ramas del poder público, con el objetivo de generar un cambio de dirección (el arrepentimiento significa, precisamente, un cambio de dirección) para lograr la protección efectiva de esos derechos. Esa cooperación debe incluir un diálogo sobre los niveles y modos de satisfacción de los derechos fundamentales sociales en un momento determinado, dada la limitación de los

64 Véase, entre otras, las siguientes sentencias de la Corte Constitucional colombiana: T-153/1998, T-388/13, T-282/14, T-762/15 y T-197/17.

65 Sentencia T-25/04.

66 Véase, entre otras, la Sentencia T-760/08.

67 Katharine Young, Constituting Economic and Social Rights, Oxford, Oxford University Press, 2012.

68 Aoife Nolan, "Ireland: The separation of powers doctrine vs. socio-economic rights", en Malcolm Langford (ed.), Social Rights Jurisprudence: Emerging Trends in International and Comparative Law, Cambridge, Cambridge University Press, 2009.

69 David Landau, "The reality of Social Rights Enforcement", Harvard International Law Journal 53 (1) (2012); Octavio Ferraz, "Health inequalities, rights and courts: The social impact of the "judicialization of health' in Brazil”, en Alicia E. Yamin y Siri Gloppen (eds.), Litigating Health Rights: Can Courts Bring More Justice to Health?, Cambridge Mass., Harvard University Press, 2011, cap. 4. 
recursos financieros. También puede comprender un análisis conjunto de datos e información empírica útil para diagnosticar la situación de los titulares de derechos y, con periodicidad, la eficacia de las medidas implementadas. ${ }^{70}$

La Sentencia T-91 de 2018, de la Corte Constitucional de Colombia, ofrece un ejemplo acerca de cómo los jueces pueden desempeñar esta función catalizadora. Diez estudiantes de secundaria de una pequeña ciudad pobre en una región devastada por el conflicto armado interno colombiano solicitaron a las autoridades educativas que abriera una escuela secundaria en su ciudad. Debido a restricciones de carácter financiero, un decreto establece que se puede abrir un curso de escuela secundaria solo si hay un minimo de 22 estudiantes. La Secretaría de Educación del Departamento del Caquetá, con base en esta disposición, negó la solicitud. Posteriormente, los estudiantes presentaron una acción de tutela en la que solicitaban la protección de su derecho fundamental a la educación.

La Corte Constitucional revisó el caso y tenía, al menos, tres posibilidades de decisión. Primero, podría haber seguido la tendencia de la primera jurisprudencia constitucional sudafricana y diferir la decisión de las autoridades politicas. Segundo, podría haber emitido una medida fuerte y, después de haber declarado la inconstitucionalidad del decreto, haber ordenado a las autoridades que abrieran la escuela secundaria. Mientras que la primera alternativa no habría protegido el derecho de manera eficiente, la segunda habría significado una fuerte interferencia en las políticas educativas y en el manejo de los recursos financieros para la educación. En cambio, la Corte siguió una estrategia catalizadora. Durante el proceso, la Corte inició un diálogo significativo con las autoridades educativas. El Tribunal indagó sobre las posibilidades existentes para ofrecer a los estudiantes cupos en escuelas secundarias en ciudades aledañas. La Secretaría de Educación identificó dos escuelas secundarias a 20 kilómetros de distancia, en donde los estudiantes podrían continuar con su formación. En la sentencia, la Corte ordenó a las autoridades políticas iniciar un diálogo significativo con los demandantes para acordar dos asuntos: en qué escuela secundaria los estudiantes continuarian su educación y cómo las autoridades educativas financiarían el transporte. El compromiso entre los demandantes y las autoridades fue muy fructifero. Después de unos dias, lograron un acuerdo. Los estudiantes ahora están matriculados en una escuela secundaria y el gobierno municipal está financiando el transporte.

$70 \quad$ En el ámbito de la adjudicación de los derechos fundamentales sociales, Young habla sobre el rol catalizador de un tribunal en un sentido más amplio. En su concepción, este rol abarca diferentes estrategias de control judicial: "respetuosa, conversacional, experimentalista, gerencial y perentoria”. Según Young, esas estrategias "abren un escenario de acción, más allá de los tribunales y las ramas elegidas, para situar a la Corte dentro de una red de relaciones que involucra a los litigantes, beneficiarios de derechos que se encuentran en una situación similar a los litigantes, otras partes que resultarán perjudicadas o beneficiadas por la acción judicial, y el público en general" (Katharine Young, "A typology of economic and social rights adjudication: Exploring the catalytic function of judicial review”, International Journal of Constitutional Law 8 (3) (2010), p. 391). 


\section{EL PAPEL CATALIZADOR DE LOS JUECES Y LOS LÍMITES PARA ENMENDAR LA CONSTITUCIÓN}

Los jueces deben estimular a las autoridades politicas para preservar la democracia constitucional en los procesos de reforma constitucional. Una reforma constitucional es un caso especial de cambio constitucional formal, el cual es una modificación en el conjunto de normas constitucionales válidas. Los cambios constitucionales pueden ser formales o informales. La diferencia entre disposiciones y normas constitucionales facilita la comprensión de estas dos modalidades. ${ }^{71}$ Las disposiciones constitucionales son los enunciados de una constitución. En el caso de las constituciones escritas, el conjunto de significados expresados por las disposiciones constitucionales son las normas constitucionales; ${ }^{72}$ dichos significados pueden articularse en proposiciones prescriptivas que establecen que algo está ordenado, prohibido o permitido constitucionalmente, o que otorgan un poder constitucional o una inmunidad a alguien.

Los cambios constitucionales formales implican una modificación en una o más disposiciones de la Carta. Su efecto es una reforma en el conjunto de normas constitucionales válidas. En contraste, un cambio constitucional informal se refiere a aquella modificación que se genera en el conjunto de normas constitucionales válidas, sin que se cambien las disposiciones constitucionales. La mutación constitucional por interpretación, ${ }^{73}$ la mutación infraconstitucional ${ }^{74} \mathrm{y}$ la desuetud constitucional ${ }^{75}$ son tipos de cambio constitucional informal.

Hay tres tipos básicos de cambios constitucionales formales: promulgación, reforma y derogación de una constitución. Los textos constitucionales suelen regular los procedimientos de reforma constitucional. Esta es una estrategia institucional para equilibrar dos objetivos intrínsecos a la promulgación de una constitución que a veces están en tensión: por un lado, las constituciones buscan la estabi-

71 Sobre la distinción entre disposición y norma en derecho constitucional, véase Vezio Crisafulli, “Disposizione (e norma)”, XIII Enciclopedia del Diritto 165 y 203 (1964). Asimismo, en el ámbito de los derechos fundamentales, véase Robert Alexy, A Theory of Constitutional Rights, Oxford, Oxford University Press, 2002, p. 32.

72 El hecho de ser el significado expresado por una disposición constitucional es una condición suficiente, pero no necesaria, para que las normas constitucionales sean tales. También existen normas constitucionales que expresan el significado de convenciones constitucionales, principios, normas, prácticas o prácticas constitucionales no escritas.

73 Este concepto se refiere al caso en el que los jueces atribuyen un nuevo significado a una antigua disposición constitucional. Con respecto a un contexto no relacionado con el estado, Arato ha demostrado cómo el cambio constitucional informal puede tener lugar en cualquier práctica legislativa y política de interpretación constitucional, además de la práctica de interpretación de los jueces (Julián Arato, "Treaty interpretation and constitutional transformation: Informal change in international organizations", Yale Journal of International Law 38 (2013), p. 304).

74 Este concepto se refiere al cambio que se produce mediante la promulgación de leyes ordinarias, la ratificación de tratados internacionales, la ejecución de acciones ejecutivas o la puesta en escena de prácticas políticas que, a pesar de ser incompatibles con la constitución, no se cuestionan en los tribunales judicialmente ni son declaradas inconstitucionales. Sobre este concepto, véase Carlos Bernal, "Informal constitutional change”, American Journal of Comparative Law 62 (2014), p. 495.

75 Sobre la desuetud constitucional, véase Richard Albert, "Constitutional amendment by constitutional desuetude”, American Journal of Comparative Law 62 (2014), p. 641. 
lidad política y jurídica mediante la consolidación de la estructura del Estado y de algunos principios, normas y derechos; por otro, permiten a las autoridades constituidas responder a nuevas demandas sociales mediante la modificación de las disposiciones de la Constitución. ${ }^{76}$

El concepto de reforma constitucional es ambiguo. "Reforma constitucional" se refiere a cualquier cambio constitucional formal que se promulga al seguir adecuadamente las reglas constitucionales para la reforma. Las reformas constitucionales pueden tener diferentes grados de intensidad, alcance y propósito. Aquellas que son profundas y amplias pueden deshacer una constitución e, incluso, destruir la institucionalización del constitucionalismo democrático. Por esta razón, la literatura y la jurisprudencia de diversas jurisdicciones han utilizado los conceptos de "revisión" constitucional, ${ }^{77}$ "desmembramiento", 78 "sustitución" y "reemplazo" para designar reformas constitucionales que implican alteraciones más profundas de los elementos constitucionales esenciales, esto es, la identidad o la estructura básica de la Constitución. Además, los autócratas pueden usar -y lo han hechoreformas constitucionales para destruir el constitucionalismo democrático. Estas reformas los perpetúan en el poder o disminuyen los controles y equilibrios, y los mecanismos de responsabilidad política y jurídica. Esto es lo que David Landau denomina "constitucionalismo abusivo", ${ }^{79}$ una práctica que genera el riesgo de destrucción del constitucionalismo democrático, bajo la apariencia de una reforma de la Constitución. ${ }^{80}$

Desde el punto de vista del diseño institucional, los constituyentes pueden adoptar dos estrategias extremas. Por un lado, si quieren buscar estabilidad politica y jurídica o crear un mecanismo sólido para prevenir el constitucionalismo abusivo, pueden adoptar procedimientos de reforma rígidos y muy exigentes. Por otro, si los creadores de la Constitución quieren permitir que las autoridades constituidas respondan a las nuevas demandas sociales mediante el cambio de las disposiciones constitucionales, pueden establecer procedimientos flexibles para reformarla.

76 En El Federalista 43. Madison argumentó que el artículo V de la Constitución estadounidense logró un equilibrio entre esos objetivos: "protege igualmente contra esa facilidad extrema que haria a la Constitución demasiado mutable; y esa extrema dificultad que podría perpetuar sus defectos descubiertos" (James Madison, “The Federalist No. XLIII”, en Alexander Hamilton, John Jay y James Madison, Federalist, on the New Constitution, New York, B. Warner, 1817, p. 239).

77 Para una discusión iluminadora sobre las diferencias entre la revisión constitucional y la reforma constitucional, véase Richard Albert, "Amendment and revision in the unmaking of constitutions”, en David Landau y Hanna Lerner (eds.), Handbook on Comparative Constitution-Making, Cheltenham: Edward Elgar, en prensa, en https://papers.ssrn.com/sol3/papers2.cfm?abstract_ id=2841110, fecha de consulta: 12 de marzo de 2018. Véase también, Donald S. Lutz, "Toward a theory of constitutional amendment”, American Political Science Review 88 (2) (1994), p. 356.

78 Richard Albert, “Constitutional amendment and dismemberment”, Yale Journal of International Law 43 (2018)

79 Sobre el concepto de constitucionalismo abusivo, véase David Landau, "Abusive constitutionalism”, University of California Davis Law Review 47 (2013), pp. 189-200; y Rosalind Dixon y David Landau, “Constraining constitutional change”, Wake Forest Law Review 50 (2015), pp. 859-890.

80 Sobre el argumento de la apariencia, véase David Landau, "The importance of constitution-making”, Denver University Law Review 89 (3) (2011-2012), pp. 611-633. 
Ambas estrategias crean riesgos innegables. Si la Constitución prevé un solo procedimiento de reforma y este es demasiado exigente desde el punto de vista democrático, el riesgo de que las reformas constitucionales destruyan el constitucionalismo democrático o menoscaben la Constitución es bajo. Sin embargo, las autoridades políticas lucharán para adaptar la Constitución a nuevas realidades o para corregir errores. Tendrán que recurrir a cambios constitucionales informales. Esto podría llevar a una evasión de la democracia en la actualización de la Constitución. Si, como ocurre en países como Estados Unidos, la interpretación constitucional y la mutación son la forma habitual de actualizar la Constitución, las personas y sus representantes se ven privados de la oportunidad de deliberar sobre posibles modificaciones a la Carta.

Sin embargo, si los procedimientos de reforma son demasiado accesibles, entonces las autoridades politicas no enfrentarán problemas para actualizar la Constitución, pero, al mismo tiempo, podrían destruir fácilmente el constitucionalismo democrático o deshacer la Constitución mediante una reforma.

Una estrategia que goza de creciente popularidad alrededor del mundo se basa en la doctrina de las reformas constitucionales inconstitucionales. ${ }^{81}$ La base de esta doctrina es el reconocimiento de que existen limites explícitos o implícitos al poder de reforma constitucional. Mientras que las cláusulas pétreas institucionalizan limites explícitos, los tribunales han reconocido limitaciones implícitas. Una forma de hacer que esos limites sean exigibles es el control constitucional de las reformas constitucionales. Esta estrategia implica que los jueces anulen las reformas constitucionales con fundamentos sustantivos cuando estas alteren la estructura básica de la Constitución, su identidad o sus elementos esenciales, de manera que esta pueda considerarse reemplazada o sustituida por otra. Los antecedentes de este tipo de control constitucional son la doctrina india de la estructura básica de la Constitución ${ }^{82}$ y la doctrina de la sustitución constitucional de la Corte Constitucional colombiana. ${ }^{83}$

81 Yaniv Roznai, Unconstitutional Constitutional Amendments. The Limits of Amendment Powers, Oxford, Oxford University Press, 2017.

82 Desde el caso Kesavananda Bharati v. State of Kerala, AIR 1973 SC 1461, la Corte Suprema de Justicia de la India ha sostenido que el poder de reforma del Parlamento no implica la autorización para cambiar la estructura básica de la Constitución. En el caso Minerva Mills Ltd. v. Union of India, AIR 1980 SC 1789, esa Corte vinculó el concepto de estructura básica con la idea de identidad de la Constitución. Una pregunta debatida sigue siendo: ¿qué elementos pertenecen a la estructura básica? Véase Sudhir Krishnaswamy, Democracy and Constitutionalism in India: A Study of the Basic Structure Doctrine, Oxford, Oxford University Press, 2011, p. 71 f. Véase también, Madhav Khosla, "Constitutional amendment", en Sujit Choudhry, Madhav Khosla y Pratap Bhanu Mehta, The Oxford Handbook of the Indian Constitution, Oxford, Oxford University Press, 2016, pp. 232250. Sobre la doctrina de la estructura básica desde una perspectiva comparada, véase Aharon Barak, "Unconstitutional constitutional amendments", Israeli Law Review 44 (2011), pp. 321-341.

83 Sentencias C-970 y C-971/2004, C-1040/2005, C-588/2009, C-141 y C-397/2010, C-574/2011, C-170, C-249, C-288, C-317 y C-1056/2012, C-010 y C-579/2013, C-577/2014 y C-332/2017. Para una explicación crítica de esta doctrina, véase Carlos Bernal, "Unconstitutional constitutional amendments in the case study of Colombia: An analysis of the justification and meaning of the constitutional replacement doctrine", International Journal of Constitutional Law 11 (2) (2013), pp. 339-357. 
Como explica Roznai, ${ }^{84}$ los jueces están difundiendo el uso de esta doctrina en todo el mundo. Pero ¿cómo deberían los jueces emprender este tipo de control? Una vez más, aquí hay varias posibilidades. Primero, los jueces podrian ser muy respetuosos respecto de las reformas constitucionales que llevan a cabo las autoridades politicas, independientemente de la forma en que se concierten y de su impacto en la democracia constitucional. En segundo lugar, siempre podrían ejercer un control judicial intenso para prevenir el constitucionalismo abusivo y preservar la democracia.

Una tercera vía podría provenir de una alternativa catalizadora. A lo largo del tiempo, en la práctica del control constitucional de reformas constitucionales, los tribunales pueden exhortar a las autoridades politicas a llevar a cabo una deliberación justa e inclusiva para reformar la constitución y, en particular, las disposiciones referidas a los elementos esenciales del constitucionalismo democrático. De esta manera, los jueces podrían establecer dos reglas de ponderación:

- Cuanto más se modifiquen los elementos esenciales del constitucionalismo democrático o de la constitución mediante una reforma constitucional, mayor deberá ser la deliberación durante el procedimiento para aprobarla.

- Cuanto menos deliberación justa e inclusiva haya durante el procedimiento de una reforma constitucional, más intenso deberá ser el control judicial de la reforma.

La Sentencia C-332 de 2017 de la Corte Constitucional de Colombia proporciona un ejemplo de la forma en que una Corte puede ejercer su función catalizadora aplicando esas reglas. En esa sentencia, la Corte controló una reforma constitucional que establecía un procedimiento especial de fast track para la implementación del Acuerdo de Paz suscrito en 2016 entre el Gobierno colombiano y las Fuerzas Armadas Revolucionarias de Colombia (FARC). Las características esenciales de ese procedimiento incluían: el monopolio gubernamental de la facultad de presentar proyectos de ley para reformas constitucionales y leyes; la reducción a la mitad del número de debates exigidos para la aprobación de reformas constitucionales (cuatro en lugar de ocho debates) y de leyes (dos en lugar de cuatro debates); que las modificaciones introducidas por los congresistas a los proyectos de ley presentados por el Congreso no serían válidas sin la aprobación del Gobierno; y la exigencia de que los proyectos de ley se votaran en su totalidad, lo que prohibía la práctica de votar cada disposición.

Los miembros del principal partido político de oposición cuestionaron la constitucionalidad de las dos últimas características. Apelaron a la doctrina de las reformas constitucionales inconstitucionales señalando que las disposiciones del Acto Legislativo 1/2016 sustituyeron parcialmente un principio constitucional esencial, a saber, la separación de poderes. La aprobación de las modificaciones por parte

84 Yaniv Roznai, Unconstitutional Constitutional Amendments. The Limits of Amendment Powers, op. cit. 
del Gobierno y el voto en bloque facultaban excesivamente al Poder Ejecutivo, en detrimento de las competencias del Congreso.

En su sentencia, la Corte Constitucional aplicó su doctrina de la sustitución de la Constitución y declaró la inconstitucionalidad de estas dos características del procedimiento fast track. Ciertamente, la Corte reconoció que la constitucionalidad de los instrumentos de justicia transicional debería analizarse utilizando estándares más flexibles. Sin embargo, también sostuvo que, incluso desde este punto de vista, la aprobación de las modificaciones por parte del Gobierno y la votación en bloque eran limitaciones desproporcionadas a la separación de poderes y la democracia deliberativa. En esas condiciones, el Congreso no podría llevar a cabo una deliberación legislativa plena, que además garantizara el pluralismo político y los derechos políticos de las minorías. Además, para la Corte fue particularmente significativo que el Congreso hubiera aprobado esa reforma constitucional sin deliberar al respecto. El partido de la oposición, que había ganado un plebiscito rechazando el Acuerdo de Paz, se había negado a votar esa reforma constitucional. Así, la Corte rechazó la reforma para catalizar la democracia deliberativa en la implementación del Acuerdo de Paz.

\section{CONCLUSIONES}

En este artículo defendí la tesis según la cual, la Biblia institucionaliza un sistema de separación de poderes entre diferentes autoridades: Dios, el rey, los jueces y los profetas. Asimismo, enfaticé la relevancia de la función catalizadora de los profetas, quienes cumplian esta función al dialogar con el rey para animarlo a actuar de forma virtuosa, en aras de la búsqueda del bien común y la protección de los intereses del pueblo.

También aduje que esta función debe ser la base de un modelo de separación de poderes apropiado para el constitucionalismo democrático. En este modelo, los jueces deben desempeñar una función catalizadora y deben actuar de forma no invasiva. Antes bien, deben hacer visibles desde el punto de vista jurídico y político problemas sociales soslayados y deben crear incentivos para que las autoridades politicas persigan el bien común y protejan los derechos fundamentales. Algunos ejemplos muestran cómo un ejercicio semejante de la función judicial catalizadora conduce al respeto de las competencias del legislativo y el ejecutivo y, a la vez, a alcanzar sus fines últimos.

\section{BIBLIOGRAFÍA}

Albert, Richard, "Amendment and revision in the unmaking of constitutions", en David Landau y Hanna Lerner (eds.), Handbook on Comparative Constitution-Making, Cheltenham, Edward Elgar (en prensa), en https://papers. ssrn.com/sol3/papers2.cfm?abstract_id=2841110, fecha de consulta: 12 de marzo de 2018. 
Albert, Richard, "Constitutional amendment and dismemberment”, Yale Journal of International Law 43 (2018), en https://digitalcommons.law.yale.edu/cgi/ viewcontent.cgi?article $=1685 \&$ context $=y j i l$

Albert, Richard, "Constitutional amendment by constitutional desuetude", American Journal of Comparative Law 62 (2014), p. 641, en https://lawdigitalcommons.bc.edu/cgi/viewcontent.cgi?referer=https://www.google.com/\&httpsre $\operatorname{dir}=1 \&$ article $=1757 \&$ context=lsfp

Alexy, Robert, A Theory of Constitutional Rights, Oxford, Oxford University Press, 2002.

Arato, Julián, "Treaty interpretation and constitutional transformation: Informal change in international organizations", Yale Journal of International Law 38 (2013), p. 304, en https://papers.ssrn.com/sol3/papers.cfm?abstract_ id $=2142083$

Aristóteles, Política, Libro IV, Capítulo 14, en http://classics.mit.edu/Aristotle/ politics.4.four.html, fecha de consulta: 2 de agosto de 2019.

Barak, Aharon, "Unconstitutional constitutional amendments", Israeli Law Review 44 (2011), pp. 321-341. DOI: https://doi.org/10.1017/S0021223700018082

Bernal, Carlos, "Informal constitutional change", American Journal of Comparative Law 62 (2014), p. 495. DOI: https://doi.org/10.5131/AJCL.2014.0017

Bernal, Carlos, "Unconstitutional constitutional amendments in the case study of Colombia: An analysis of the justification and meaning of the constitutional replacement doctrine", International Journal of Constitutional Law 11 (2) (2013), pp. 339-357. DOI: https://doi.org/10.1093/icon/mot007

Bilchitz, David y David Landau, "Introduction: The evolution of the separation of powers in the Global South and Global North", en David Bilchitz y David Landau (eds.), The Evolution of the Separation of Powers. Between the Global North and the Global South, Cheltenham, Elgar, 2018.

Bilchitz, David, Poverty and Fundamental Rights: The Justification and Enforcement of Socio-Economic Rights, Oxford, Oxford University Press, 2007.

Crisafulli, Vezio, “Disposizione (e norma)”, XIII Enciclopedia del Diritto 165 y 203 (1964).

Dixon, Rosalind y David Landau, "Constraining constitutional change", Wake Forest Law Review 50 (2015), pp. 859-890, en https://ssrn.com/abstract=2624842

Ferraz, Octavio, "Health inequalities, rights and courts: The social impact of the 'judicialization of health' in Brazil”, en Alicia E. Yamin y Siri Gloppen (eds.), Litigating Health Rights: Can Courts Bring More Justice to Health?, Cambridge Mass., Harvard University Press, 2011.

Garoupa, Nuno, "Comparing Judicial Activism - Can we Say that the US Supreme Court is more Activist than the German Constitutional Court", Revista portuguesa de filosofia 72 (4) (2016), pp. 1089-1105, en https://ssrn.com/ abstract $=2887650$ 
Jung, Courtney, Ran Hirschl y Evan Rosevear, "Economic and social rights in national constitutions", American Journal of Comparative Law 62 (4) (2014), en https://papers.ssrn.com/sol3/papers.cfm?abstract_id=2349680

Khosla, Madhav, "Constitutional amendment”, en Sujit Choudhry, Madhav Khosla y Pratap Bhanu Mehta, The Oxford Handbook of the Indian Constitution, Oxford, Oxford University Press, 2016.

Kramer, Larry, The People Themselves: Popular Constitutionalism and Judicial Review, Oxford, Oxford University Press, 2004.

Krishnaswamy, Sudhir, Democracy and Constitutionalism in India: A Study of the Basic Structure Doctrine, Oxford, Oxford University Press, 2011.

Landau, David, “Abusive constitutionalism”, University of California Davis Law Review 47 (2013), pp. 189-200, en https://lawreview.law.ucdavis.edu/issues/47/1/articles/47-1_Landau.pdf

Landau, David, “The importance of constitution-making”, Denver University Law Review 89 (3) (2011-2012), pp. 611-633, en https://ssrn.com/abstract=1950405

Landau, David, "The reality of social rights enforcement", Harvard International Law Journal 53 (1) (2012), en https://harvardilj.org/2012/01/issue_53-1_landau/

Locke, John, Two Treatises of Government, en P. Laslett (ed.), Cambridge, Cambridge University Press, 1988.

Lutz, Donald S., "Toward a theory of constitutional amendment", American Political Science Review 88 (2) (1994), p. 356. DOI: https://doi.org/10.2307/2944709

Madison, James, “The Federalist No. XLIII”, en Alexander Hamilton, John Jay y James Madison, Federalist, on the New Constitution, New York, B. Warner, 1817.

Montesquieu, El espíritu de las leyes, Libro XI, en https://oll.libertyfund.org/titles/montesquieu-complete-works-vol-1-the-spirit-of-laws, fecha de consulta: 2 de agosto de 2019.

Nolan, Aoife, "Ireland: The separation of powers doctrine vs. socio-economic rights”, en Malcolm Langford (ed.), Social Rights Jurisprudence: Emerging Trends in International and Comparative Law, Cambridge, Cambridge University Press, 2009.

Pillay, Anashri, "Economic and social rights adjudication: Developing principles of judicial restraint in South African and the United Kingdom", Public Law 3, (2013).

Roznai, Yaniv, Unconstitutional Constitutional Amendments. The Limits of Amendment Powers, Oxford, Oxford University Press, 2017.

Schlafty, Phyllis M., The Supremacist: The Tyranny of Judges and Hot to Stop it, Dallas, Spence, 2004.

Steinberg, Carol, "Can reasonableness protect the poor? A review of South Africa's socio-economic rights jurisprudence”, South African Law Journal 123 (2006), en https://journals.co.za/content/ju_salj/123/2/EJC53695 
Tushnet, Mark, Weak Courts Strong Rights: Judicial Review and Social Welfare Rights in Comparative Constitutional Law, Princeton, Princeton University Press, 2009, pp. x-xi.

Versteeg, Mila y Emily Zackin, "Constitutions unentrenched: Towards an alternative theory of constitutional design", American Political Science Review 110 (2016), p. 657.

Waldron, Jeremy, "The core of the case against judicial review", The Yale Law Journal 115 (2006), en https://digitalcommons.law.yale.edu/ylj/vol115/iss6/3/

Waluchow, Wil, "Constitutionalism”, en Edward N. Zalta (ed.), The Stanford Encyclopedia of Philosophy, 2018, en https://plato.stanford.edu/archives/spr2018/ entries/constitutionalism/, fecha de consulta: 25 de enero de 2019.

Wenzel, James P., Shaun Bowler y David J. Lanoue, "Legislating from the state bench: A comparative analysis of judicial activism", American Politics Quarterly 25 (1997), pp. 363-379. DOI: https://doi.org/10.1177/1532673X9702500306

Young, Katharine, "A typology of economic and social rights adjudication: Exploring the catalytic function of judicial review", International Journal of Constitutional Law 8 (3) (2010). DOI: https://doi.org/10.1093/icon/moq029

Young, Katharine, Constituting Economic and Social Rights, Oxford, Oxford University Press, 2012. 